\title{
El intelectual universitario censurado en España
}

The university intellectual censored in Spain

\author{
Ignacio Álvarez Rodríguez \\ Profesor Contratado Doctor (E.R.I) de Derecho Constitucional \\ Universidad Complutense de Madrid \\ Correo electrónico: ialvarez1@ucm.es \\ Código ORCID: https://orcid.org/0000-0001-6873-7269
}

Fecha de recepción: febrero 11 de 2021

Fecha de aprobación: junio 15 de 2021

Para citar este artículo / To reference this article

Álvarez, I. (2021) El intelectual universitario censurado en España. Inciso, 23(1) e:1083

DOI: http://dx.doi.org/10.18634/incj.23v.1i.1083

\section{Resumen}

El texto es un análisis jurídico-constitucional del boicot que sufrió un filósofo del Derecho español en una Universidad pública también española cuando se disponía a dar la conferencia de clausura de un Congreso científico (un caso de eso que se denomina cultura de la cancelación o no-platforming, en expresión acuñada en los campus norteamericanos). La metodología que se sigue es una metodología deductivo-lógica donde se dan las razones y argumentos que se extraen tanto desde la perspectiva jurídica como desde la perspectiva académica, no sólo de lo pernicioso que resulta para el debate público que se censure a expertos que van a discutir con otros colegas en público ciertas tesis de interés común, sino de la ilicitud de tales comportamientos, hallazgos de los cuales se extrae la principal conclusión del trabajo: tanto desde la perspectiva de la libertad de expresión como desde la óptica de la libertad académica y de cátedra, las políticas de cancelación de turbas más o menos organizadas debieran ser perseguidas por las autoridades académicas, cuya defensa del intelectual que ejerce sus derechos fundamentales debería ser una prioridad indubitada en un espacio público. 
Palabras clave: universidad, Constitución, cultura de la cancelación, intelectuales, profesor, censura.

\section{Abstract}

The text is a legal-constitutional analysis of the boycott suffered by a philosopher of Spanish Law in a public university also Spanish at the time when he was preparing to give a closing conference of a scientific Congress (culture of cancellation or no-platforming, in expression coined in North American campuses). The methodology that is followed is a deductive-logical methodology where the reasons and arguments that are extracted from both the legal perspective and the academic perspective are given, not only from how harmful it is for the public debate to censor experts who go to discuss with other colleagues in public certain theses of common interest, but of the illegality of such behaviors, findings from which the main conclusion of the work is drawn: from the perspective of freedom of expression and from the perspective of academic freedom and chair, the cancellation policies of more or less organized mobs should be pursued by the academic authorities, whose defense of the intellectual who exercises his fundamental rights should be an undoubted priority.

Key words: University, Constitution, cancel culture, intellectuals, lecturer, censorship.

\section{Introducción}

El presente texto es un reflexión en voz alta sobre lo que le sucedió -más bien lo que le hicieron-a Pablo de Lora, prestigioso filósofo del Derecho español que presta servicios en la Universidad Autónoma de Madrid. Los hechos de autos acaecieron en la Universitat Pompeu i Fabra en diciembre de 2019, en un caso de censura de eso que los estadounidenses llaman no-platforming (HAIDT y LUKIANOFF, 2019; DE LORA, 2019a; BARENDT, 2007). A tal fin se expone, en primer término, los antecedentes inmediatos del caso. En segundo término, se explica el propio caso, cuáles fueron los hechos y las consecuencias del supuesto. En tercer lugar, reflexionamos sobre sus implicaciones tanto desde el punto de vista constitucional como desde una perspectiva algo más amplia, a la que llamaremos no constitucional. Se finaliza con unas conclusiones sobre los hallazgos que deja un caso tan polémico y desagradable como el que tuvo sufrir el jurista, siempre sometidas al sano debate doctrinal.

\section{Antecedentes}

En los últimos tiempos hemos vivido en España algunos episodios que resultan sumamente complicados de entender en general y especialmente si suceden como sucedieron dentro de una Universidad. Casos donde determinadas actividades científicas se vieron cuestionadas por diferentes grupos de personas cuyo principal objetivo era que la actividad no se celebrase (DUDDA, 2019: 121; GARTON, 2017). El nexo que unía todas las diatribas censoras era 
en última instancia que la actividad atentaba, presuntamente, contra la igualdad y la no discriminación de la mujer o contra la dignidad e igualdad de los colectivos LGTBI. También se han dado casos donde se alegaba como razón primordial el respeto a las víctimas del terrorismo. Eso sucedió en diciembre de 2019 cuando la Universidad del País Vasco permitió (en aras de la "libertad de expresión" según sus propias palabras) la conferencia de un etarra recién excarcelado, que acudió a exponer su visión sobre "los derechos de los reclusos que sufren enfermedades graves". El caso guarda dos diferencias con los que se van a exponer aquí. La primera es que el grupo que protestaba contra la misma no intentó boicotearla cuando ya se tenía certeza de que se celebraría, manifestándose a las puertas del recinto. La segunda es la fuerte presencia policial que había en los alrededores, hecho este que, llegado el caso, cuyo auxilio no deberían descartar las autoridades académicas si se pone en riesgo la celebración del acto y con ello la seguridad de los participantes (THOMPSON, 2017: 334).

El primer antecedente inmediato acaeció en la Universidad de La Coruña, en septiembre de 2019. Las jornadas a celebrar tenían como objeto de análisis la prostitución. Determinados colectivos feministas criticaron duramente que la visión que se iba a defender era la llamada "regulacionista" y eso era intolerable, por cuanto se blanqueaba lo que era uno de los principales modos de opresión de la mujer en el mundo moderno. Se creó un hashtag \#UniversidadSinProstitución, donde se afirmaban cosas como que el evento académico no era sino una "estrategia del lobby proxeneta para captar a chicas jóvenes y educar a los nuevos puteros" (PÉREZ, 2020: 59). La Universidad emitió un comunicado donde alegaba que no podía garantizar la seguridad ni la calidad académica del debate, amén de dar cuenta del "fuerte rechazo, hostigamiento y crueldad" sufrido en redes sociales, una vez se anunció la celebración del evento. De otro lado, casi un centenar de profesoras firmaron un manifiesto defendiendo la libertad de investigación y alertando de una "grave vulneración de la libertad de expresión". Las jornadas terminaron por celebrarse en el Centro Social A Comuna y no en la Universidad.

El segundo antecedente inmediato tuvo lugar en noviembre de 2019. La Universidad Carlos III de Madrid iba a auspiciar un evento científico que también tenía por objeto diversas reflexiones en torno a la prostitución. Una organización estudiantil denominada Frente de Estudiantes anunció unos días antes que boicotearía el evento. Aunque lo intentaron y llegaron a las puertas de la sala, las jornadas se celebraron finalmente, en un ambiente un tanto hostil y enrarecido. Pero la mecha estaba ya prendida.

Con el terreno abonado, el Barcelona Institute of Analytic Philosophy (BIAP), institución de prestigio internacional creada por la Universidad de Barcelona, la Universidad Pompeu i Fabra y la Universidad de Girona, convocó la celebración de unas jornadas sobre transexualidad los días 18 y 19 de diciembre de 2019. Invitaron para ello, entre otros, a un experto en la materia como el profesor Pablo de Lora, filósofo del Derecho que imparte magisterio en la Universidad Autónoma de Madrid. Lo que sucedió a continuación no sabemos si sorprenderá al lector pero desde luego debería inducir a una severa y serena reflexión. Si esos son los derroteros por los que se van a encauzar los debates intelectuales en el siglo XXI no parece haber mucho margen para la duda y la razón -argamasa de toda discusión que se precie- y sí lo habrá para la consolidación de una forma de ser y de estar en el mundo que sólo permitirá que nos 
manejemos según los dictados de los neoinquisidores de turno (MARTí y MORESO, 2020; DE LORA, 2019b).

Un caso, como se verá, de puro desprecio a la cultura del Estado de derecho, en la medida en que este se basa en una serie de valores morales que confluyen en una idea capital: las diferencias que haya que solventar -por lo demás inevitables en la medida en que la interacción y convivencia humana son inherentemente conflictivas- se ajustarán a las leyes y no a lo que dicten los prejuicios de un puñado de personas. Parecía que después de todo lo acaecido en el siglo XX habíamos trazado un consenso básico en torno al gobierno de las normas por encima del gobierno de las personas (PEÑA, 2020: 96; GARCÍA FIGUEROA, 2019 y 2020).

\section{El caso del profesor de Lora}

La sala de reuniones presenta un aspecto envidiable. Está iluminada y es amplia y espaciosa. Se da la palabra el profesor de Lora para que inicie su ponencia y, en ese momento, entran en la sala un grupo de personas que se distribuyen rodeando la mesa y enfrente del ponente. Llevan pancartas donde se lee "machista”. Otras rezan “misoginia”. También "fuera transfobia".

Un par de lo que parecen esteladas adornan el paisaje. Distribuyen pasquines a lo largo y ancho del recinto en los que reiteran los calificativos al filósofo del Derecho. El motivo que aducen es una entrevista que el jurista había dado, en septiembre al diario El Mundo, donde vertía opiniones sobre el feminismo que, a lo que se vio, no eran de su agrado. Sobre el libro que acababa de publicar, un exhaustivo trabajo científico que discute algunas de las derivas del feminismo actual, la algarada no se pronuncia. El asunto llegaba cebado, dado que algunas personas caldearon previamente el ambiente en redes sociales, campaña en la que incluso participó una compañera de profesión del afectado, quien retuiteó los tuits donde se abogaba por boicotear la conferencia y quien, participando en el acto, no tuvo a bien hacerle saber al interesado cual era el motivo de su discrepancia (SOTO, 2017).

El profesor De Lora intenta iniciar su presentación, pero no le dejan. Sentado en el lugar reservado a los ponentes, observa cómo la algarada se sitúa a su espalda, en el estrado, para leer un manifiesto, cosa que se les permitió (y luego ya no cejaron en el empeño). Pablo de Lora abandona su puesto y se sienta junto a varios colegas para escucharlos. A partir de ahí, los discrepantes invitan a todo el mundo a abandonar el aula, pide intervenir otra persona y el caos acaba reinando, pues varios profesores solicitan a la turba que pare.

Media hora más tarde desde el inicio de los hechos, el profesor de Lora pide la palabra y acaba por desistir. Dice no entender que lo que está sucediendo suceda en la Universidad y lo hace de la forma más honesta, pausada y reflexiva que puede, dadas las circunstancias. Confiesa no estar en condiciones de poder dar la conferencia y pone a disposición de quienes quieran discutir sus ideas la presentación con la que iba a desarrollarla, dado que los acontecimientos habían agotado su tiempo de intervención. El profesor De Lora abandona el acto y los saboteadores aplauden entre algunas risas (que, en realidad, parecen nerviosas y poco convencidas). La compañera que tiene a su lado, visiblemente compungida, le pregunta si 
le acompaña a la salida. Chesterton dijo que "es a menudo un error estratégico silenciar a un hombre, porque deja al mundo bajo la impresión de que tiene algo que decir" (CHESTERTON, 2018: 255). Queda fuera de toda duda el interés científico del trabajo del afectado, del cual puede hacerse una idea quien lo desee consultando sus diversos perfiles académicos en repositorios como Academia y Dialnet, entre otros muchos.

Pablo de Lora reflexionó días después sobre el episodio (SOTO, 2019). Con un poso de tristeza no exenta de preocupación, el filósofo del Derecho recordaba que con actos así se siembra el caldo de cultivo perfecto para el totalitarismo, al confluir una "masa de tibios asustados, una minoría enfervorizada, y una institución rendida". Para quien piense que estas cuestiones pecan de exageración le pondremos el ejemplo de uno de los pensadores más en boga en la actualidad, Yuval Noah Harari, quien tuvo serias dudas sobre si publicar o no su último libro para evitar dar munición a la ola populista iliberal. Afortunadamente, como él mismo dice, "elegí la discusión libre frente a la autocensura". Este tipo de dudas solo florecen cuando algo de veras se remueve en los cimientos de una democracia (HARARI, 2018: 17). 0, dicho con las palabras de otro experto en estas lides, "una universidad es el último lugar del mundo donde debería permitirse que triunfaran nunca el veto individual, subjetivo, del estoy ofendido, el veto del asesino o el veto del reventador" (GARTON, 2017: 223). Varios medios escritos dieron cuenta de lo que sucedió y apoyaron al profesor, criticando el comportamiento de la turba. Algunos editoriales y artículos de opinión lo defendieron públicamente y otro tanto hicieron varios colegas de profesión mediante un manifiesto de dominio público para el lector interesado.

Desde el propio BIAP se emitió una declaración pública por parte de su Director, donde se reconoce una "restricción de la expresión académica", defendiendo la libre expresión, la libre discusión de ideas y reconociendo que, aunque los manifestantes tenían derecho a protestar, este derecho no puede anular el ejercicio del anterior (MARTí y MORESO, 2019).

\section{Algunas posibles causas}

Intentado comprender algo que en verdad roza lo incomprensible, se aventuran ahora algunas razones que podrían contextualizar este tipo de comportamientos. No sin antes aclarar dos cosas. En primer lugar es necesario recordar que la democracia liberal española intenta atender las demandas de diferentes colectivos y grupos que podríamos llamar vulnerables, aun con sus a buen seguro muchos errores e imperfecciones. En segundo lugar, que compartimos sin fisuras el criterio de un conocido y prestigioso politólogo de Harvard, cuando dice que "la única sociedad que puede tratar a todos sus miembros con respeto es aquella en la que cada individuo goce de derechos individuales basados en su condición de ciudadano, no en su pertenencia a ningún grupo particular" (MOUNK, 2018: 25).

Una primera causa de este tipo de comportamientos es que suelen anteponer las consideraciones ideológicas a cualesquiera otras, incluyendo la libertad de debatir con el que se está en desacuerdo (OVEJERO, 2018; GRACIA, 2018). En tal escenario se destruye la posibilidad de toda ciencia y de todo progreso, que no pueden avanzar sin proceso contradictorio. En caso de que esos valores ideológicos entren en colisión con otros derechos y libertades, los que están detrás de estas acciones suelen dirimir el conflicto unilateral e 
irrevocablemente a favor de aquellas. Ya lo dijeron afamadísimos escritores hace algunos años: tendemos a ver todo a través de la lente del yo y el equilibrio suele venir en la madurez saliendo paulatinamente de ese yo y de ponerse en la piel de los demás (FOSTER, 2014). Entendemos que en el caso de autos la principal causa que se reivindicaba era algo así como el feminismo y la transexualidad (aunque es obvio que ninguno de tales movimientos políticos como tal tienen responsabilidad ni culpa alguna en lo que hagan ciertas personas en su nombre), creyendo que su defensa exigía silenciar las tesis del jurista. Ya han podido comprobar que nada más lejos de la realidad. Por dos motivos. El primero es bastante obvio pero no por ello menos importante: la monografía científica del autor sigue a disposición del público, como no puede ser de otra forma. El segundo tiene que ver con el despliegue, una vez más, del llamado efecto Streisand: si no se desea dar pábulo a un mensaje lo mejor es permitirlo, no prohibirlo o censurarlo (GAMPER, 2019: 131).

Una segunda causa es el auge de la política identitaria, muy presente en diversas ramas y disciplinas de las ciencias sociales de ayer y hoy (PENNY, 2018; RORTY, 2019; PETERSON, FRY, GOLDBERG, y DYSON, 2019). Pero no una política identitaria común, donde se defienden esos mínimos que nos conectan a todos los seres humanos, sino una política identitaria cada vez más excluyente, articulada exclusivamente en torno a la idea de grupo, atomizada y caracterizada por el efecto centrifugadora: expulsar del centro a todos los que no comulguen con sus exigencias; y estas cada vez son mayores a la par que muy brumosas, cuando no fijadas con cierta arbitrariedad (RORTY, 2019: 73; y VALDEON, 2019: 19). A Pablo de Lora le reprochaban que no era trans y que por lo tanto no podía hablar de la realidad transexual. Tal cual suena. Para más inri, la actitud de los saboteadores reproduce lo mismo que dice criticar. Esto es: se proclaman víctimas y no tienen otra forma de demostrarlo que creando nuevas víctimas. Con esa actitud solo dejan lugar a que tales "victimazgos" entren en competición por ver quién es peor tratado, quien es más víctima.

Una tercera causa tiene que ver, en estrecha relación con lo que se acaba de decir, con el auge del debate en torno a la corrección política (DUDDA, 2019; PETERSON, FRY, GOLDBERG, y DYSON, 2019). Desde algunas voces que dicen defender a los llamados colectivos vulnerables suele darse pábulo a este tipo de comportamientos porque de esta manera -cercenando el discurso, impidiendo su desarrollo- creen que se les protege de eventuales efectos nocivos. Contraste el lector ese motivo con la respuesta que le dio Chesterton hace ya varios años a estas cuitas: "Si el libre pensamiento significa que no somos libres de rebatir a los librepensadores, es que nos encontramos ante una forma muy sesgada de libre pensamiento" (CHESTERTON, 2018: 255).

Este tipo de planteamientos suelen ser proclives a alegar, en diferentes grados y con algunos matices, discurso del odio. El valor a proteger sería -sin negar la vertiente individual- una suerte de dignidad colectiva, que incide en las características que diferencian al colectivo en cuestión (la homosexualidad a los homosexuales, la transexualidad a los transexuales, etc). Silenciando el discurso se les protege de recibir algo que se presupone va a ser un daño (RORTY, 2019: 70; MOUNK, 2019: 209; LILLA, 2018). 
Si se profundiza en esta cuestión veremos que el asunto adquiere una dimensión mayor, toda vez que la corrección política es trasunto de una serie de debates que hoy en día se fraguan en torno a la libertad de expresión, que es tanto como decir en torno a la democracia. La democracia, vaya también por delante, no tiene nada que ver con balsas de aceite, consensos absolutos, verdades sagradas y ritos incuestionables. Una verdadera democracia es una democracia donde se producen desacuerdos, no donde no existen. Una verdadera democracia está en constante ebullición, lo que sucede es que canaliza sus discrepancias pacíficamente y sin lesionar los derechos de las minorías (RUNCIMAN, 2019: 247; KEANE, 2018: 842).

Por un lado destacan los defensores de la libertad de expresión a ultranza, sin límites (ese libertario "llamar a las cosas por su nombre"). Son los mismos que defienden que se debe permitir cualesquiera expresiones, incluso las ofensivas, concepto este que tienden a arrumbar porque lo consideran muy poco serio y menos riguroso conforme a lo que luego se dirá (COETZEE, 2007; GARTON, 2017: 219). Este sector aprovecha la más mínima ocasión para hablar de los "ofendiditos", esas personas que, dicho en Román paladín, alegan una hipersensibilidad que la vida en sociedad no tolera y que pretenden hacer valer a toda costa su adscripción identitaria: mujer, homosexual, transgénero, queer, inmigrante, negra, lo que toque. No cualquier identidad, no toda identidad: sólo la que puede considerarse que ha sido discriminada y violentada por el patrón mayoritario que las ha preterido. El patrón normativo a seguir sería el que ha marcado tradicionalmente el varón blanco heterosexual (GAMPER, 2019). Todo lo que no sea eso ha servido para juntar a personas "diferentes" y crear a su albur una identidad basada en lo emocional, en la subjetividad y en las intersecciones de opresión, las cuales dan lugar a varias discriminaciones simultáneas. El responsable y culpable siempre es el sistema, que es tanto como decir el mentado varón blanco heterosexual.

Por otro lado, tenemos a los críticos de la libertad de expresión a ultranza capitaneados por filósofos como Jason Stanley, quien señala que este tipo de visiones son una seña característica de los fascismos contemporáneos (STANLEY, 2018; LIJTMAER, 2019). Argumenta el filósofo que, por un lado, reclaman para sí la capacidad de estar constantemente nombrado las cosas como quieran (y lamentando el hecho de haber perdido la posición de poder privilegiado que ostentaban hasta hace bien poco: se les ha movido el suelo que pisaban y, por ello, respiran por la herida, evocando un pasado mítico añorado). Por otro, son los primeros que alzan la voz cuando se produce el impedimento, o lo que estiman como tal, llevando hasta sus últimas consecuencias aquello que dijo Orwell de que la auténtica libertad de expresión es decirle a la gente lo que no quiere oír. Es así como posamos la mirada en el otro lado del cuadrilátero, donde vemos quienes defienden que la libertad siempre tiene límites, reivindicación tanto más enérgica cuando se trata de actores políticos que han logrado posicionar sus ideas en la agenda política tales como \#MeToo; \#BlackLivesMatter; o \#Cuéntalo.

Este sector cree que a la hora de regular la libertad de expresión debería tenerse en cuenta el principio del daño (reformulado en la doctrina norteamericana gracias a autores como Mackinnon o a Waldron en torno al concepto de dignidad). Para ello parten de la base de que la idea de libertad, ya desde formulaciones como la de John Stuart Mill, tenía un límite claro: provocar daño a otros. La cuestión quedaba así reducida a algo en realidad irreductible: 
es imposible saber qué es ese "daño a otro". ¿Es un daño objetivo o subjetivo? ¿Quién lo determina? ¿Cómo se demuestra? ¿Se puede pedir a alguien que "demuestre" que algo como decir "existen denuncias falsas" o "todos los hombres son violadores" le causa daño? ¿Hay que hacer que sea la ley quien lo determine? ¿O mejor hacemos recaer este tipo de casos en los jueces, quienes probablemente acaben por decidir en base a criterios morales? Algunos autores norteamericanos arguyen que en casos extremos los jueces siempre acaban por aplicar los fines morales que justifican la decisión que toman para el derecho que está en litigio. Por ejemplo, el Juez Johnson así lo hizo cuando permitió la marcha encabezada por Martin Luther King desde Selma hasta Montgomery contra el criterio del Gobierno de Alabama: lo hizo porque entendía que la causa era justa. Esto es, a grandes males, más margen para la libertad de expresión, con jueces que no sentencian (ni podrán hacerlo) de forma neutral (SANDEL, 2008: 315).

Resumiendo: tenemos personas y colectivos basados en criterios identitarios que piden ser respetados alegando los mismos motivos que en su día fueron los que, según su argumento, hicieron de ellos unas víctimas oprimidas. En consecuencia, la libertad de expresión se debe modular en base a este respeto. Por otra parte, tenemos personas y colectivos que defienden que la libertad de expresión debe prevalecer ante todo y por encima de todo. Ante la duda de si este tipo de actitudes se pueden entender desde una sola coordenada ideológica, todo apunta a que hay simpatizantes de todos lados, aunque se vislumbra que cierta izquierda peca un poco más (OVEJERO, 2018; LILLA, 2018; GRACIA, 2018).

Una cuarta causa tiene que ver con el hecho de exportar lo peor de determinados modelos. El ejemplo paradigmático es lo que sucede en algunas Universidades norteamericanas. Los ejemplos que aporta la doctrina son abundantes y obligan a replantearse seriamente estas derivas (HAIDT y LUKIANOFF, 2019). Algunos de estos centros se han rodeado de todo tipo de garantías que, aun con buena intención, acaban por hacer un daño importante a la comunidad universitaria. En lugar de apostar por la libertad de expresión auténtica, la que posibilita la defensa de todos los puntos de vista y, especialmente, el de aquellos que no piensan como nosotros, intentan proteger con tanta intensidad a los estudiantes que al final acaban por contribuir a perpetuar un estado de adolescencia que, cuando se abandona, suele venir con arrobas extra de dolor y confusión. En algunos casos se pide que los académicos lleven a cabo un trigger warning; en otros se han creado safe spaces para intentar amortiguar eventuales incomodidades del día a día universitario; también se han dado casos donde el conferenciante no ha podido dar la charla de turno, incluso llegando a secuestrar al equipo decanal en el despacho del decano. Dicho lo anterior, no todos los centros universitarios presentan este tipo de políticas y de problemas, claro está. La mejor doctrina nos explica que eso sucede porque el marxismo se queda sin adeptos dentro de la Universidad. Al hilo de mayo del 68, profesores y estudiantes empiezan a tener una inclinación por lo identitario, que viene a rellenar el hueco que deja aquel. Esto tiene dos posibles lecturas. Una muy positiva, puesto ha animado a las disciplinas académicas a ampliar el alcance de sus investigaciones para incorporar las experiencias de amplios grupos que habían sido algo invisibles, como las mujeres y los afroamericanos. Y tiene otra mucho menos auténtica, a saber, alentar una fascinación obsesiva por los márgenes de la sociedad, hasta el punto de ofrecer una imagen totalmente distorsionada a los estudiantes (LILLA, 2018: 91). 
En quinto lugar, es imposible que este tipo de comportamientos se reproduzcan si no se goza de la no diremos connivencia, pero sí de la pasividad tácitamente permisiva de las autoridades académicas. Los alborotadores sólo repiten su comportamiento si entienden que no han hecho nada malo y si no hay ningún tipo de consecuencia derivada de sus acciones. Que suceda esto en la principal sede del debate y la discusión, donde se hace ciencia y donde se discute sobre esa ciencia, donde se investiga y se debe seguir investigando, sólo nos deja ante un panorama desolador. Un auténtico terreno baldío y yermo en lo intelectual. A lo peor este tipo de conductas en el fondo muestran una verdad, y es que la militancia política y la discusión académica libre son como el agua y el aceite (ESTEBAN, 2019; VARGAS, 2012: 37).

\section{Implicaciones constitucionales y no constitucionales}

El profesor de Lora y los organizadores del evento gozaban de la razón en Derecho. Esto se entenderá mejor si se repara en el hecho de que lo allí tenía lugar era un ejercicio claro de la libertad de expresión, y de la libertad científico-académica (CHUECA, 2008). Además, el profesor de Lora y los organizadores del evento tenían también razón desde un punto de vista ético-moral, teniendo en cuenta que los hechos sucedieron en la Universidad. Iremos primero al argumento constitucional y luego al argumento académico y universitario.

\section{Desde el punto de vista de la Constitución}

Las implicaciones constitucionales son claras. El profesor de Lora vio lesionados sus derechos fundamentales a la libertad de expresión y a la libertad científico-académica, ambos reconocidos como derechos fundamentales en el artículo 20 de la Constitución Española.

Respecto a la libertad de expresión, la interpretación que ha hecho nuestro Tribunal Constitucional ha sido ampliamente protectora. Aunque tenga algunas sentencias discutibles, no podemos permitir que los árboles nos impidan ver el bosque: de más de trescientas sentencias donde ventila casos relacionados con este derecho fundamental, la regla general ha sido su protección y reconocimiento. Se habla de la STC 226/2016, donde el deber de lealtad hacia el partido político pesa más que la libertad de expresión de la afiliada (SALVADOR, 2019). Esa protección ha sido cimentada en torno a algunos principios básicos que conviene recordar. En primer lugar, los límites que se contemplan en el artículo 20.4 CE deben ser interpretados de forma restrictiva. De lo contrario la libre expresión como derecho fundamental se vacía de contenido. El tan de moda "discurso del odio" es una excepción absolutamente excepcional: las sentencias que determinan que el discurso de autos era "del odio" y, por ende, no entraba dentro de los márgenes de protección constitucional no llegan siquiera a muestra representativa (TERUEL, 2019; URÍAS, 2019).

Hasta donde sabemos, el TC sólo ha empleado en dos ocasiones esta noción. Una, respecto al enaltecimiento del terrorismo, en la STC 112/2016, asunto que ha generado aceradas críticas doctrinales (CABELLOS, 2018: 79). Otra, respecto a la quema pública de fotos de los Reyes de España, en la STC 177/2015, resolución esta última declarada contraria al artículo 10 del Convenio Europeo de Derechos Humanos por el Tribunal de Estrasburgo (STEDH 13/3/2018), y también sometida a crítica por nuestra comunidad de expertos (PRESNO, 2018; BILBAO, 2018). Dos de un total de más de trescientas cuarenta resoluciones sobre libertad de 
expresión. Es más, incluso en los casos más sensibles que suelen ser proclives a polémicas enconadas, como los que tenían por objeto saber si era constitucional o no la punición penal de la negación del genocidio, el Tribunal Constitucional optó por una visión realmente amplia de la libertad de expresión, sosteniendo que negar el genocidio -no justificarlo o adherirse ideológicamente a él- entraba dentro de sus márgenes y así lo dijo en la STC 235/2007, aunque esta fue cuestión muy discutida en sede doctrinal (DÍEZ-PICAZO, 2021). Todo lo que se acaba de decir ha quedado confirmado con la resolución dictada en el caso Strawberry en la STC 35/2020, donde el Pleno ha decidido que las expresiones que el cantante vertió en redes sociales y que le valieron la condena en el Tribunal Supremo a un año de cárcel por enaltecer el terrorismo entran dentro de su derecho fundamental a la libertad de expresión y no constituyen delito alguno. Es más, incluso cuando nuestro Juez Constitucional ha adoptado una interpretación restrictiva de este derecho fundamental no abusa de la noción, como por ejemplo sucede en el caso de la bandera de España, decidido por la STC 190/2020.

En segundo lugar, el derecho fundamental a la libertad de expresión no es sólo un derecho subjetivo de las personas, sino que es un derecho fundamental que goza de una posición preferente en caso de conflicto con otros -especialmente respecto al derecho al honor, intimidad, y propia imagen, aunque no solo- por su vertiente objetiva: contribuye a la conformación de la opinión pública, clave de bóveda de una auténtica democracia (GÓMEZ, 2018). Este parece haber sido uno de los criterios clave a la hora de decidir el mencionado caso Strawberry y, también, en el caso del torero que falleció en una plaza de toros y sufrió el calificativo de "asesino" momentos después en redes sociales. En mayo de 2021 supimos que el Tribunal Constitucional entendía que tal expresión en dicho contexto no entraba en el derecho a la libre expresión.

En tercer lugar, no hay casos similares a lo que le sucedió al profesor de Lora que hayan llegado al conocimiento de la jurisdicción constitucional. Lo más parecido -e insistimos, no lo es- es el caso de un profesor de la Universidad de La Laguna que escribió un artículo de opinión incisivo para con la gestión del Rector y fue sancionado disciplinariamente. El Tribunal Constitucional entendió en la STC 101/2003 que, a pesar de que se pudiera no compartir las opiniones vertidas y el tono fuera duro, no insultaba a nadie, por lo que la sanción impuesta por la Universidad había lesionado el derecho fundamental del docente. En la STC 161/2005 se ventilaba la constitucionalidad del despido de un Decano de una Facultad Universitaria. EI TC entiende que, en realidad, no hay tal conflicto: Ia sentencia de instancia declaraba que el despido venía motivado por desobedecer una orden del rector y el recurrente pretendía que la jurisdicción constitucional revisara la misma, lo cual excede de sus competencias (FJ 5). Esto nos lleva a uno de los asuntos fundamentales respecto de la libertad de expresión. El único límite real, claro y sostenido en el tiempo que nuestro Juez de la Constitución ha establecido desde el año 1981 hasta el presente 2021 es el insulto. Es decir, una vez llevado a cabo el discurso se analiza si ha sido insultante o no. Si lo es, el artículo 20 CE no ampara al insultante. Si no lo es, el artículo $20 \mathrm{CE}$ ampara al hablante. Pero para eso hay que dejar que el interesado se explaye, no impedirlo. Dicho con otras palabras: el impedir que un ponente dé su ponencia no protege a nadie de nada, sino que intenta prevenir un presunto daño que nunca se ha causado. Huelga decir que el insulto, en el caso del malogrado torero antes comentado, nos libera de realizar ulteriores comentarios. 
Respecto a la libertad científica el Tribunal Constitucional se ha pronunciado en muchas menos ocasiones. En concreto, y directamente, en tres (DÍEZ-PICAZO, 2021). La primera vez que lo hizo fue en la STC 26/1987, para declarar que en el artículo 27.10 CE se configura un auténtico derecho fundamental y no (no sólo) una garantía institucional. La autonomía universitaria es un derecho fundamental y el fundamento y justificación de tal aseveración es "el respeto a la libertad académica, es decir, la libertad de enseñanza, estudio e investigación" (FJ 4). Si nos preguntamos por el contenido esencial de ese derecho fundamental, el Tribunal Constitucional nos aclara que está formado "por todos los elementos necesarios para el aseguramiento de la libertad académica" (FJ 5). Aun pudiendo discutir los argumentos de la resolución -fue objeto de tres votos particulares y de críticas doctrinales aceradas- el fondo es loable: dotar a la autonomía universitaria de las mayores garantías procesales y sustantivas que nuestra Constitución prevé, tal y como ha interpretado la doctrina constitucionalista de largo, resaltando que la autonomía universitaria siempre debe servir a la libertad de cátedra y académica (TORRES, 2005: 53). Léase, para el caso que aquí nos ocupa: el profesor de Lora y los organizadores del evento se encontraban en una institución ampliamente protegida por el Derecho Constitucional vigente, protección que en este caso permitía o incluso exigía que se hubieren adoptado las medidas necesarias para poder celebrar el evento.

La segunda vez que el Tribunal Constitucional se ocupó de esta libertad fue en la STC 43/2004. La defensa cerrada que realiza de la libertad científica, en concreto de la ciencia historiográfica, condujo a que declarase su prevalencia respecto al derecho al honor del demandante. EI TC dijo para quien quisiera leer la resolución que si la obra en cuestión se ajustaba a los cánones científicos al uso (y el documental impugnado en autos se ajustaba), en esas circunstancias prevalecía sobre el derecho honor, extremo que no ha quedado exento de crítica doctrinal (CLAVERO, 2019). Entendemos y asumimos que el supuesto de hecho y la litis del proceso eran diferentes a lo acaecido en la Universitat Pompeu i Fabra. Aun así, no se ven razones para no poder subsumirlo en esta línea jurisprudencial. Léase, para el caso concreto: el profesor de Lora quedaba amparado por la Constitución para poder exponer sus tesis científicas en el foro en cuestión porque sus opiniones no eran meras ocurrencias ni opiniones carentes de fundamento -lo cual también gozaría de amparo constitucional- sino fruto de un exhaustivo trabajo científico.

La tercera vez que el Tribunal Constitucional se pronuncia fue en la STC 235/2007, donde se ventila la constitucionalidad de la tipificación del delito de negación del genocidio. Cuando el legislador penal decide introducir como delito la negación o justificación del genocidio, por lo demás un claro discurso del odio con raigambre en el Convenio Europeo de Derechos Humanos interpretado a la luz de los criterios del Tribunal de Estrasburgo (LÓPEZ, 2021; TERUEL, 2019), el Tribunal Constitucional llega a la conclusión de que la "mera negación" del genocidio es libertad de expresión (FJ 8). Incluso en uno de los casos más extremos, el TC entendió que la libertad de expresión debía ser protegida frente a otros valores y bienes jurídicos.

Reza un conocido aforismo del Derecho Administrativo que quien puede lo más puede lo menos. Para nuestro caso, si la negación del genocidio no puede ser motivo para castigar penalmente a nadie, ¿desde qué lugar constitucional se pudo negar al profesor de Lora 
que llevara a cabo su discurso? En suma, si un filósofo del Derecho sigue los patrones investigadores de su disciplina, publica una monografía sobre la materia, se le invita en calidad de experto para que exponga en público y en un foro académico algunas de sus tesis, la conclusión que se deriva es más que clara: está plenamente amparado por nuestra Constitución para que lo haga.

\section{Desde el punto de vista de la Universidad}

Desde la perspectiva de la Universidad, la actitud que tuvieron los participantes en el escrache a Pablo de Lora fue sintomática de algunos males que aquejan a la institución; de no atajarse, corremos el riesgo de destruir uno de los principales foros de debate que tenemos en nuestras sociedades.

No cabe duda de que Universidad y democracia van de la mano. Las democracias son abiertas y pluralistas o no son democracias. Por ende, las Universidades pueden y deben debatir en libertad acerca de las muchas visiones que tenemos sobre el mundo. Es peligroso que sólo se pueda debatir sobre lo que deciden unos pocos (PARDO, 2016). Queremos hacer hincapié en el quid de la cuestión: hablamos de un discurso académico, a desarrollar por un académico, en el ámbito académico. Pablo de Lora compareció en calidad de universitario. Los saboteadores, no tanto. De ahí que algunos filósofos hayan defendido de forma convincente la necesidad de llevar extramuros de la Universidad las disputas políticas (GARCÍA MORENTE, 2012). Y de ahí que, con igual razón, algunas pensadoras creen que un discurso potente se contrarresta con otro aún más potente, no prohibiendo o censurando (PAGLIA, 2018).

Otro insumo que conviene tener en cuenta es la importancia de las emociones, las cuales copan progresivamente cada vez más espacios universitarios. Aunque la razón conduce a pensar que lo ideal es permitir que en un evento académico todas las opiniones puedan ser escuchadas y, en base a eso, sacar las conclusiones propias, las emociones se filtran y con ellas el asunto da un giro de 180 grados. ¿Por qué motivo? Por la sencilla razón de que se deja que tomen el mando. Ahora siento que el ponente ha dicho cosas en una entrevista que me ofenden, o que ofenden al colectivo que represento, o que ofenden a mi/su/nuestra dignidad. Ni siquiera le concedo el beneficio de la duda -idea esta que es ilustrada, claro (TODOROV, 2008; PINKER, 2018; ECO, 2018)- para que pueda exponer su hipótesis y yo, en el turno de palabra, poder matizarle lo que mejor estime. Nada más lejos de la realidad.

Entiéndase bien lo que se quiere decir. Ni las emociones son ilegítimas ni son algo "menor" comparado con las razones. Sencillamente hay que aceptar que razones y emociones conviven en cada uno de nosotros y que hay que aplicar algunas reglas que nos permitan convivir de la mejor posible con esa mezcolanza. Para ello, podemos utilizar el criterio que defiende uno de nuestros mejores pensadores (OVEJERO, 2020: 266). Por un lado, las emociones no resuelven los dilemas morales y, cuando actuamos en base a ellas, nada impide que seamos castigados si cometemos un ilícito. Por otro, conviene retener que las emociones son falibles dado que a veces nos ayudan a decidir correctamente y a veces nos conducen a todo lo contrario. 
Este tipo de actitudes resultan especialmente graves porque consiguen minar cuando no destruir la esencia universitaria, que por si lo hemos olvidado implica universalidad, una comunidad de personas, alumnos y maestros reunidas en torno a la búsqueda de la verdad (GAMPER, 2019). No habría ciencia ni progreso si no hubiera discusión. Es tan sencillo o tan complicado como eso. Y para quien quiera caer en la tentación de creer que así se consigue atacar una de las líneas de flotación del liberalismo, que se interrogue por los motivos de que esa búsqueda de la verdad se ha llevado a cabo al menos veinticinco siglos antes del actual $y$, por ende, mucho antes de que el liberalismo existiera, al menos en su acepción moderna (WARBURTON, 2019; RUIZ, 2019).

Por último, cabe recordar que este tipo de actitudes lanzan un mensaje peligroso y especialmente preocupante. Porque da la sensación -se admite estar equivocado, como en el resto del escrito- de que los participantes en el boicot ven al profesor de Lora más como un enemigo civil que como un conciudadano del que discrepar. Un tipo al que hay que combatir y destruir (¿qué se hace sino con los enemigos contra los que libramos las batallas?) más que un experto que merece refutación. Como dice Fernando Savater: en democracia todo el mundo tiene derecho a estar equivocado, pero nadie lo tiene para extirpar el error (SAVATER, 1997: 180). Ya se sabe: errare human est y nadie es infalible. Lo que sucedió en la Universidad aquel día - lo que le hicieron a Pablo De Lora, recordemos- reproducía en alguna medida la clásica dicotomía entre las personas buenas (ellos) y las personas malvadas (el profesor de Lora), síntoma este que está carcomiendo algunas Universidades y, a nada que nos descuidemos, nuestra sociedad (GERCHUNOFF, 2019).

\section{Conclusiones}

Después de las líneas anteriores, se pueden sintetizar algunas reflexiones finales a modo de conclusión final, que sometemos al mejor parecer de la comunidad científica.

Teniendo en cuenta que el boicot contra actos académicos en Universidades tiene algunos antecedentes remotos y cercanos, la última versión en España ha llegado de la mano del que sufrió el profesor Pablo de Lora en la Universitat Pompeu i Fabra en diciembre de 2019. El boicot fue agitado previamente en redes sociales al hilo de una entrevista que concedió el profesor de Lora a un diario de tirada nacional. Algunas personas advirtieron en varios hilos que estábamos ante un machista, un misógino y un tránsfobo. Llegado el día de la intervención del filósofo del Derecho, un grupo de personas irrumpió con carteles donde se reiteraban tales calificativos, leyendo un manifiesto y, finalmente, impidiéndole hablar. Este hubo de abandonar el acto y la Universidad.

Se ha intentado contextualizar las causas del fenómeno. Por un lado, este tipo de actitudes suelen tener la ideología por encima de cualquier consideración académica o científica y una acusada tendencia identitaria, intensificada en el marco de los debates que sobre la corrección política y la libertad de expresión están sucediéndose. Además, exportan lo peor del modelo universitario norteamericano, dando legitimidad al no-platforming con la consiguiente ruptura de la comunidad universitaria y de sus fines, ante lo que suele ser la pasividad de las autoridades académicas (quienes en el caso concreto del profesor de Lora intentaron que el conferenciante pudiese hablar, sin éxito). 
Las implicaciones son en todo caso profundas. Por un lado, las que hemos denominado constitucionales. Según el razonamiento de líneas anteriores al profesor de Lora se le lesionaron sus derechos fundamentales a la libertad de expresión y a la libertad científica. Además, están las implicaciones universitarias. Si la Universidad es uno de los principales foros donde discutir los desacuerdos científicos, esta debería ir en dirección opuesta a actitudes que buscan ante todo la confrontación siguiendo la peligrosa senda del enemigo, también conocida como el nosotros contra ellos.

Además, este tipo de acciones son ineficaces. Consiguen lo que se proponen a muy corto plazo (que la conferencia no se celebre) pero no a medio y a largo plazo (la comunidad académica sigue adelante, investigando los asuntos que nos preocupan y defendiendo, si procede, discursos molestos). En el intervalo de una situación a otra, han lesionado derechos fundamentales de un ciudadano que comparece en un foro académico en calidad de experto, esperando poder desarrollar sus tesis y someterlas a un debate "abierto, robusto y libre". Por no mencionar el coste personal y psicológico propio de alguien que solo intentaba hacer su trabajo lo mejor posible.

\section{Referencias bibliográficas}

Barendt, E. (2007). Freedom of Speech. Oxford University Press.

Bilbao, J.M (2018). La STEDH de 13 de marzo de 2018 en el asunto Stern Taulats y Roura Capellera contra España: La crónica de una condena anunciada”. Revista General de Derecho Constitucional, 28.

Cabellos, M.Á. (2018). Opinar, enaltecer, humillar: respuesta penal e interpretación constitucionalmente adecuada en el tiempo de las redes sociales. Revista Española de Derecho Constitucional, 11.

Chesterton, G.K. (2018). Un buen puñado de ideas. Editorial Renacimiento.

Chueca, R (2008). El derecho fundamental a la investigación científica. Revista Electrónica del Departamento de Derecho de la Universidad de La Rioja, 6.

Clavero, B. (2019). Constitución a la deriva. Imprudencia de la justicia y otros desafueros. Ediciones Pasado y Presente.

Coetzee, J.M (2007). Contra la censura. Ensayos sobre la pasión por silenciar. Debate.

De Lora, P. (2019a). Lo sexual es político (y jurídico). Alianza Editorial.

De Lora, P. (2019b). Libertad académica: mi experiencia (trans)formativa. Letras Libres, 215.

Díez-Picazo, L.Ma (2021). Sistema de derechos fundamentales. Tirant lo Blanch.

Dudda, R. (2019). La verdad de la tribu. La corrección política y sus enemigos. Debate.

Eco, U. (2018). Contra el fascismo. Lumen. 
Foster Wallace, D. (2014). Esto es agua. Algunas ideas, expuestas en una ocasión especial, sobre cómo vivir con compasión. Random House.

Gamper, D (2019). Las mejores palabras. De la libre expresión. Anagrama.

García Figueroa, A.J. (2019). Feminismo de Estado: fundamentalmente religioso y religiosamente fundamentalista. Eunomía. Revista de Cultura en la Legalidad, 17.

García Figueroa, A.J. (2020). Populismo y Feminismo de Estado. En Martín, T; y Velasco, J.M (eds). El fortalecimiento de los derechos ciudadanos. Tirant lo blanch.

García Morente, M (2012). El ideal universitario y otros ensayos, EUNSA.

Garton Ash, T. (2017). Libertad de palabra. Diez principios para un mundo conectado. Tusquets.

Gerchunoff, S. (2019). Ironía On. Una defensa de la conversación pública de masas. Anagrama.

Gómez Sánchez, Y. (2018). Derechos fundamentales. Aranzadi.

Gracia, J. (2018). Contra la izquierda. Para seguir siendo de izquierdas en el siglo XXI. Anagrama.

Haidt, J; y Lukianoff, G. (2019). La transformación de la mente moderna. Deusto.

Harari, Y.N. (2018). 21 lecciones para el siglo XXI. Debate.

Kaiser, Á (2020). La neoinquisición. Persecución, censura y decadencia cultural en el siglo XXI. Deusto.

Keane, J. (2018). Vida y muerte de la democracia. Fondo de Cultura Económica.

Lijtmaer, L. (2019). Ofendiditos. Sobre la criminalización de la protesta. Anagrama.

Lilla, M. (2018). El regreso liberal. Más allá de la política de la identidad. Debate.

López Guerra, L. (2021). El Convenio Europeo de Derechos Humanos según la jurisprudencia del Tribunal de Estrasburgo. Tirant lo Blanch.

Mounk, Y (2018). El pueblo contra la democracia. Por qué nuestra libertad está en peligro y cómo salvarla. Paidós.

Ovejero, F. (2020). Sobrevivir al naufragio. El sentido de la política. Página Indómita.

Ovejero, F. (2018). La deriva de la izquierda reaccionaria. Página Indómita.

Paglia, C. (2018). Feminismo pasado y presente, Turner, Madrid, 2018. 
Pardo, J.L. (2016). Estudios del malestar. Políticas de la autenticidad en las sociedades contemporáneas. Anagrama.

Penny, L. (2018). Bitch Doctrine. Essays for dissenting adults. Bloomsbury.

Peña Freire, A. (2020). La constitución del Estado de derecho. Anuario de Filosofía del Derecho, 36.

Pérez, L. (2020). Maldita feminista. Hacia un nuevo paradigma de la igualdad de sexos. Seix Barral.

Peterson, J. Fry, S. Goldberg, M. Dyson, M.E. (2019). La corrección política. Planeta.

Pinker, S. (2018). En defensa de la llustración. Paidós.

Presno Linera, M.Á. (2018). Crónica de una condena anunciada: el Asunto Stern Taulats y Roura Capellera c. España sobre la quema de fotos del Rey. Teoría y Realidad Constitucional, 42.

Rorty, R. (2019). Contra los jefes, contra las oligarquías. Página Indómita.

Ruiz, J.C. (2019). El arte de pensar. Cómo los grandes filósofos pueden estimular nuestro pensamiento crítico. Almuzara.

Runciman, D (2019). Así termina la democracia. Paidós.

Salvador Martínez, Mª (2019). La libertad de expresión del afiliado a un partido político y sus límites (a propósito de la STC 226/2016). Revista Española de Derecho Constitucional, 115.

Savater, F. (1997). El valor de educar. Ariel.

Soto Ivars, J. (2017). Arden las redes. La poscensura y el nuevo mundo virtual. Debate.

Stanley, J. (2018). Facha. Cómo funciona el fascismo y cómo ha entrado en tu vida. Blackie Books.

Teruel Lozano, G. (2019). Cuando las palabras generan odio: límites a la libertad de expresión en el ordenamiento constitucional español. Revista Española de Derecho Constitucional, 114.

Thompson, M. (2017). Sin palabras. ¿Qué ha pasado con el lenguaje de la política? Debate.

Todorov, T. (2008). El espíritu de la Ilustración. Galaxia Gutenberg.

Torres Muro, I. (2005). La autonomía universitaria. Aspectos constitucionales. CEPC.

Urías, J. (2019). Libertad de expresión. Una inmersión rápida. Tibidabo Ediciones. 
Valdeón, J. (2019). “Prólogo. La resistencia”. En Khyal, L. y Un Tío Blanco Hetero. Prohibir la manzana y encontrar la serpiente. Una aproximación crítica al feminismo de cuarta generación. Deusto.

Vargas Llosa, M. (2012). La civilización del espectáculo. Alfaguara.

Warburton, N. (2019). Una pequeña historia de la filosofía, Galaxia Gutenberg. 